\title{
Structural and AC electrical properties study of solid metal urea complexes
}

\author{
Ragab Mahani* $^{*}$, Saleh D. Mekky ${ }^{\dagger}$, Badr A. El Sayed ${ }^{\dagger}$, Gamal S. EL-Bahy \\ and Azza Ward* \\ *Microwave Physics and Dielectrics Department, National Research Centre \\ 33 EL Bohouth St. (former EL Tahrir St.) Giza - Egypt - P.O. 12622 \\ ${ }^{\dagger}$ Chemistry Department, Faculty of Science, Alazhar University \\ Nasr City, Cairo, Egypt \\ ${ }^{\dagger}$ Spectroscopy Department, National Research Centre \\ 33 EL Bohouth St. (former EL Tahrir St.) Giza - Egypt - P.O. 12622 \\ \$rmsoliman66@yahoo.com
}

Received 28 February 2018; Revised 1 April 2018; Accepted 3 April 2018; Published 23 April 2018

\begin{abstract}
The complexation of solid urea with $\left(\mathrm{Co}^{2+}\right),\left(\mathrm{Cu}^{2+}\right)$ or $\left(\mathrm{Ni}^{2+}\right)$ ions has been studied by using dielectric spectroscopy technique over a wide frequency range at different temperatures. Samples' structure were investigated by XRD, FTIR and FT-Raman spectroscopy. FTIR and Raman analysis indicated that the urea coordinates with the metal atoms through the same oxygen-metal bond $(\mathrm{O}-\mathrm{M})$. Furthermore, XRD analysis showed that the samples have polycrystalline structure with single phase. The permittivity of complexes was found at much higher values than that of the ligand (pure urea), showing structure dependency. Furthermore, two relaxation peaks were observed in the dielectric loss spectra corresponding to the orientation polarization of urea molecule, and some parts of urea molecule may be $\mathrm{NH}_{2}$ groups. Both relaxation peaks correspond to thermally activated because they were shifted to higher frequency with the temperature increase. The peak position for the low frequency relaxation peak was observed at the same relaxation time $\left(\tau=7.6 \times 10^{-4} \mathrm{~s}\right)$, corresponding to the coordination mode through the same $\mathrm{O}-\mathrm{M}$ bond. Novelty of this work is the successful finding of the relationship between the crystalline phase, coordination mode and the dynamic molecular behavior of solid urea and its complexes using the dielectric spectroscopy technique.
\end{abstract}

Keywords: Urea complexes; IR; XRD; permittivity.

\section{Introduction}

Urea (U), $\left(\mathrm{NH}_{2}\right)_{2} \mathrm{CO}$ has been considered as an important organic molecule because of its potential applications in many fields. ${ }^{1-6}$ It is capable of coordinating with metallic atoms through their sites to produce metal-urea complexes. Urea and its complexes have been used in agriculture, medicine and health sciences. For instance, they have been used as fertilizers, antimicrobial, antiviral and antitumor. ${ }^{7-12}$ Urea can be prepared by the action of ammonia with alkyl carbonates, carbonyl chloride, chloroformates or urethanes. Furthermore, it is prepared industrially by allowing the liquid carbon dioxide and liquid ammonia to interact and then heating the formed ammonium carbamate at $303-383 \mathrm{~K}$ under about 35 atmospheric pressure. The molecular structure of the ligand and its complexes have been extensively studied by FT-Raman and Fourier transform infrared (FTIR). ${ }^{13-16}$ It has been reported that urea usually coordinates through the oxygen $(\mathrm{O})$ or nitrogen $(\mathrm{N})$ atom, i.e., monodentate coordination mode, while it rarely coordinates through both $\mathrm{O}$ and $\mathrm{N}$, i.e., bidentate coordination mode. ${ }^{17,18}$ Recently, the relationship between the electrical properties of urea complexes and their structure has been investigated by many authors. ${ }^{19-21}$ Direct current conductivity of the solid urea and cobalt urea complexes measured at constant voltage shows semiconductor behavior. ${ }^{22}$ The electrical properties of urea in aqueous solution have been investigated at radiowave and microwave frequencies within a temperature range (273$323 \mathrm{~K}){ }^{23}$ The result suggests that urea rotates as a single unit or monomer. Upon surveying, most available studies are mainly focused on the static dielectric measurements carried out on urea in aqueous solutions. ${ }^{24-27}$ Till now, no published work is available for correlating $\mathrm{AC}$ measurements with the molecular structure of solid urea and its complexes, namely: $\mathrm{U}, \mathrm{Co}(\mathrm{U})_{6} \mathrm{Cl}_{2}, \mathrm{Cu}(\mathrm{U})_{6} \mathrm{Br}_{2}$ and $\mathrm{Ni}(\mathrm{U})_{6} \mathrm{Br}_{2}$. Therefore, in the current study, $\mathrm{AC}$ measurements have been carried out on the solid urea complexes in order to find a correlation between the samples' dynamic molecular behavior and their molecular structure. To achieve this, an alternative electric field has been applied to urea samples over a wide frequency range between 0.1 and $10^{6} \mathrm{~Hz}$ at different temperatures. As urea samples are highly polar materials, they are polarized in the direction of electric field and their degree of polarization depends on the field frequency and the molecular structure. The permittivity as an intrinsic measure of polarization and it has been

This is an Open Access article published by World Scientific Publishing Company. It is distributed under the terms of the Creative Commons Attribution 4.0 (CC-BY) License. Further distribution of this work is permitted, provided the original work is properly cited. 
investigated for all urea samples under the conditions mentioned above. The crystalline and molecular structures of these materials have been studied by using X-ray diffraction (XRD), FTIR and FT-Raman spectroscopy.

\section{Material and Methods}

\subsection{Samples' preparation}

The metal salts and urea (U) were refluxed in ethanol from 2 to $3 \mathrm{~h}$. The following preparation of complex $\left[\mathrm{Cu}(\mathrm{U})_{6}\right] \mathrm{Cl}_{2}$ is a typical example of these preparations: $1.7048 \mathrm{gm}(0.01 \mathrm{~mol})$ of the $\mathrm{CuCl}_{2} \cdot 2 \mathrm{H}_{2} \mathrm{O}$ and $3.6 \mathrm{gm}$. $(0.06 \mathrm{~mol}$.) of urea were refluxed in $200 \mathrm{ml}$. of ethanol for $3 \mathrm{~h}$. A green precipitate was obtained while stirring, then the ethanol air-dried. The yield was $77 \%$. According to this method, the $\mathrm{U}, \mathrm{Co}(\mathrm{U})_{6} \mathrm{Cl}_{2}$, $\mathrm{Cu}(\mathrm{U})_{6} \mathrm{Br}_{2}$ and $\mathrm{Ni}(\mathrm{U})_{6} \mathrm{Br}_{2}$ were produced in the powdered form to be ready for different measurements.

\subsection{Instrumentation}

\subsubsection{X-ray diffraction}

Each urea sample was grinded in Herzog mill to reach fine powder, then $7 \mathrm{~g}$ of this powder was mixed with $1.6 \mathrm{~g}$ of binding wax in a small mill, at the speed of $380 \mathrm{cr} / \mathrm{s}$ for one minute. After that, the sample was put in an aluminum cup, then pressed in automatic pressed machine. X-ray powder diffraction data of urea and its complexes were recorded at $300 \mathrm{~K}$ using a computer controlled X-ray diffractometer (Formally made by Diano Corporation, USA) with Fe filtered $\operatorname{CoK} \alpha$. The lattice parameters were determined by introducing X-ray data with the tube operated at $45 \mathrm{KV}, 9 \mathrm{~A}$ and wavelength $1.79026 \mathrm{~nm} \operatorname{CoK} \alpha$ radiation.

\subsubsection{FTIR and FT-Raman spectra analysis}

The molecular structure of urea samples is elucidated by FTIR and FT-Raman Spectrometers. FTIR measurements were carried out using FTIR Jasco FT/IR - 430 Spectrometer at room temperature $(298 \mathrm{~K})$ in the region of $4000-400 \mathrm{~cm}^{-1}$ with a scanning speed of $2 \mathrm{~mm} / \mathrm{sec}$ and resolution $4 \mathrm{~cm}^{-1}$ in an evacuation mode using $\mathrm{KBr}$ pellets technique. FT-Raman measurements were also carried out at room temperature but in the region $3695-104 \mathrm{~cm}^{-1}$ by using FTIR/FT Raman spectrometer Nicolet, USA. The laser source is $0-2 \mathrm{~W}$ and the exposure power of the sample is $0.6 \mathrm{~W}$. The spectra were reproducible to about $1 \mathrm{~cm}^{-1}$ under similar experimental conditions.

\subsubsection{Dielectric measurements}

The dried powdered samples were individually pressed into discs $(\sim 3 \mathrm{~mm}$ thickness and $\sim 10 \mathrm{~mm}$ diameter $)$ then placed between the two electrodes of the dielectric measuring cell. The construction was connected to high-resolution impedance analyzer spectrometer Schlumberger Solartron 1260), provided with an electrometer amplifier. The dielectric measurements were carried out over a wide frequency range $\left(0.1-10^{6} \mathrm{~Hz}\right)$ and at a temperature range $(303-383 \mathrm{~K})$. The permittivity $\left(\varepsilon^{\prime}\right)$, dielectric loss $\left(\varepsilon^{\prime \prime}\right)$ and AC conductivity $\left(\sigma_{\mathrm{ac}}\right)$ were calculated from the output parameters, i.e., the capacitance $(C)$ and the dielectric loss tangent $(\tan \delta)$ as follows:

$$
\begin{gathered}
\varepsilon^{\prime}=C \frac{d}{\varepsilon_{\mathrm{o}} A}, \\
\varepsilon^{\prime \prime}=\varepsilon^{\prime} \times \tan \delta, \\
\sigma_{\mathrm{ac}}=\varepsilon_{\mathrm{o}} \omega \varepsilon^{\prime \prime},
\end{gathered}
$$

where $C(\omega)$ is the capacitance of the capacitor containing the dielectric material, $\omega$ is the angular frequency $(=2 \pi f)$ and $f$ is the frequency of the applied electrical field in Hertz. $\varepsilon_{o}=8.85 \times 10^{-12} \mathrm{~F} / \mathrm{m}$ is the vacuum permittivity. The sample geometry is denoted as thickness $(d)$ and crosssection area $(A)$. The error in $\varepsilon^{\prime}$ and $\varepsilon^{\prime \prime}$ amounts to $\pm 1 \%$ and $\pm 3 \%$, respectively. The reproducibility of the measurement was tested by re-measuring $\varepsilon^{\prime}$ and $\varepsilon^{\prime \prime}$ after performing the experiment once again.

\section{Results and Discussion}

\subsection{X-ray diffraction}

The crystalline structure studied by XRD is shown in Table 1. It is evident from the table that both urea and complexes are polycrystalline materials with single phase; tetragonal for urea and triclinic for its complexes. The unit-cell lattice parameters determined by X-ray powder data in addition to the reflection planes indexed for all urea samples using the Treo computer program ${ }^{28,29}$ are also included in Table 1 . The table shows a remarkable increase in unit cell volume upon complexation with metal ions. Furthermore, although all urea complexes have the same crystalline structure, their lattice parameters' values are different. One may attribute this to the

\begin{tabular}{|c|c|c|c|c|c|c|c|c|}
\hline \multirow[b]{2}{*}{$S^{*}$} & \multirow[b]{2}{*}{$\mathrm{P}^{*}$} & \multicolumn{3}{|c|}{ Lattice parameters } & \multirow[b]{2}{*}{$\left(V^{*}\right) \AA^{3}$} & \multicolumn{3}{|c|}{ Angles } \\
\hline & & $a$ & $b$ & $c$ & & $\propto\left(^{\circ}\right)$ & $\beta\left(^{\circ}\right)$ & $\gamma\left({ }^{\circ}\right)$ \\
\hline So & Tet.. & 5.66 & 5.66 & 4.73 & 151.4 & 90 & 90 & 90 \\
\hline $\mathrm{S} 1$ & Tric. & 11.65 & 9.32 & 15.77 & 1212.2 & 78.68 & 109.3 & 131.4 \\
\hline S2 & Tric. & 12.77 & 11.93 & 11.16 & 1252.2 & 116.9 & 75.46 & 124.2 \\
\hline S3 & Tric. & 10.23 & 8.33 & 14.44 & 1048.0 & 88.6 & 119.7 & 100.9 \\
\hline
\end{tabular}
difference in atomic and ionic radii of $\mathrm{Ni}, \mathrm{Cu}$ and $\mathrm{Co}$.

Table 1. Lattice parameters of urea and its complexes.

Notes: $\mathrm{S}^{*}, \mathrm{P}^{*}$ and $\mathrm{V}^{*}$ denotes urea samples, type of phase and unit cell volume, respectively. S0, S1, S2 and S3 denote urea, $\mathrm{Cu}(\mathrm{U})_{6} \mathrm{Br}_{2}, \mathrm{Ni}(\mathrm{U})_{6} \mathrm{Br}_{2}$ and $\mathrm{Co}(\mathrm{U})_{6} \mathrm{Cl}_{2}$, respectively. 


\subsection{Infrared and FT-Raman analyses}

FTIR analysis of all urea samples are shown in Fig. 1. Furthermore, the band locations of the most characteristic vibrations and their proposed assignments are listed in Table 2. In order to put our hand on the suggested geometrical structures of the synthesized complexes, their spectra were accurately compared with urea spectrum and some similar complexes in literatures. ${ }^{17,30-32}$ It is noticed from the figure that there are some changes in the spectral features between the pure urea (ligand) and those of urea complexes, indicating the metal ions coordination effect on the urea molecular structure. As seen in Table 2, the $3000-3600 \mathrm{~cm}^{-1}$ region shows the asymmetric and symmetric $\mathrm{NH}$ stretching bands of $\mathrm{NH}_{2}$ in the ligand located at $3472,3450,3424$ and $3180 \mathrm{~cm}^{-1}$ which generally shifts to higher wavenumbers through coordination of urea with $\mathrm{Ni}^{2+}$ and $\mathrm{Cu}^{2+}$ and

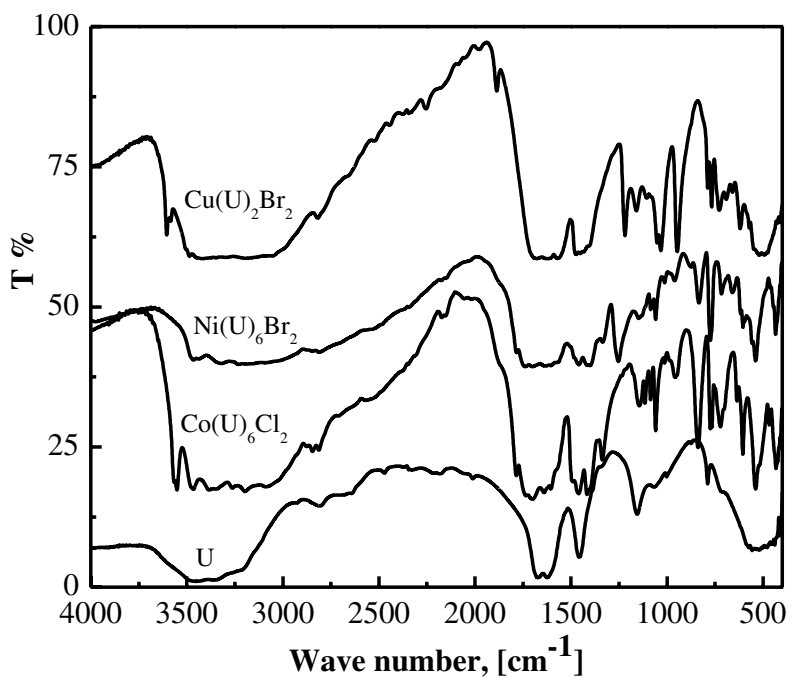

Fig. 1. Infrared spectra of urea (U) and its complexes.

Table 2. FTIR spectra and assignments of the ligand (U) and its metal complexes.

\begin{tabular}{lcccc}
\hline \multicolumn{4}{c}{ Wavenumber, $\mathrm{cm}^{-1}$} & \\
\cline { 1 - 4 } S0 & $\mathrm{S} 1$ & $\mathrm{~S} 2$ & $\mathrm{~S} 3$ & Assignment \\
\hline 3472 & 3519 & 3604 & 3550 & $\mathrm{~N}-\mathrm{H}$ stretching vibr. $(\delta \mathrm{N}-\mathrm{H})$ \\
3450 & 3427 & 3506 & 3375 & \\
3424 & 3170 & 3440 & 3261 & \\
3350 & & 3383 & 3199 & \\
3180 & & & 3168 & \\
1632 & 1656 & 1651 & 1665 & $\mathrm{~N}-\mathrm{H}$ bending vibr. \\
1470 & 1475 & 1473 & 1534 & $\mathrm{~N}-\mathrm{C}-\mathrm{N}$ stretching vibr. NH $\mathrm{N}_{2}$ rocking \\
& & & & vibr. C=O stretching vibr. \\
1412 & 1398 & 1400 & 1422, & \\
& & & 1377 & \\
1083 & 1126,1086 & 1157, & 1096 & $\mathrm{C}=\mathrm{O}$ and C-N stretching vibr. \\
& & 1107 & & \\
748 & 681 & 719 & 704 & $\mathrm{C}=\mathrm{N}$ stretching vibr. \\
\hline
\end{tabular}

$\mathrm{Co}^{2+}$ ions. This attributed to the formation of oxygen to metal bond $(\mathrm{O}-\mathrm{M})$ for all complexes which increases the contribution of highly polar structure of urea molecule (Scheme 1). Consequently, the double bond nature of $\mathrm{C}-\mathrm{N}$ bond increases and a greater single bond character for the $\mathrm{C}-\mathrm{O}$ bond. ${ }^{20} \mathrm{In}$ the $700-1653 \mathrm{~cm}^{-1}$ region, the strong band at $1632 \mathrm{~cm}^{-1}$ in urea spectrum is assigned to the $\mathrm{NH}_{2}$ bending vibration which corresponds to the reported bands at $\left(1622-1653 \mathrm{~cm}^{-1}\right)$ in the urea complexes depending on the type of metal cation and halogen ions. ${ }^{19}$ The band at $1470 \mathrm{~cm}^{-1}$ in urea is assigned to the $\mathrm{N}-\mathrm{C}-\mathrm{N}$ stretching vibration which shifts to the band $\left(1473-1534 \mathrm{~cm}^{-1}\right)$ in urea complexes. As a result, a double bond between the carbon and nitrogen is formed in the complexes $^{26}$ and thus the wavenumber increases.

As a representative example, Fig. 2 shows FT-Raman spectra of $\mathrm{U}$ (a) and $\mathrm{Cu}(\mathrm{U})_{6} \mathrm{Br}_{2}$ (b). Only a weak band is observed at $1467 \mathrm{~cm}^{-1}$ in $\mathrm{U}$ which appears with lower intensity and higher wavenumber at $1482 \mathrm{~cm}^{-1}$ in $\mathrm{Cu}(\mathrm{U})_{6} \mathrm{Br}_{2}$. This band is assigned to $\mathrm{NH}_{2}$ rocking, $\mathrm{N}-\mathrm{C}-\mathrm{N}$ and $\mathrm{C}=\mathrm{O}$ stretching vibrations and considered as an evidence of the complex formation. The weak band observed at $1178 \mathrm{~cm}^{-1}$ in urea disappeared in the spectrum of $\mathrm{Cu}(\mathrm{U})_{6} \mathrm{Br}_{2}$ and $\mathrm{Co}(\mathrm{U})_{6} \mathrm{Cl}_{2}$ which is ascribed to the motion consisting symmetric $\mathrm{C}-\mathrm{N}$ stretching, $\mathrm{NH}_{2}$ rocking and $\mathrm{C}=\mathrm{O}$ stretching. From above data analysis, the change in nature of both $\mathrm{C}-\mathrm{N}$ bond and $\mathrm{C}=\mathrm{O}$ bond confirms the coordination of metal ions through the oxygen atom of urea. ${ }^{21}$ The peak at $549 \mathrm{~cm}^{-1}$ in

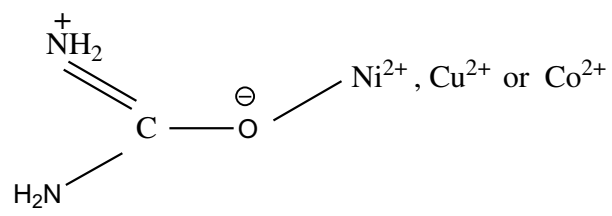

Scheme 1. Coordination of metal ions with highly polar structure of urea molecule.
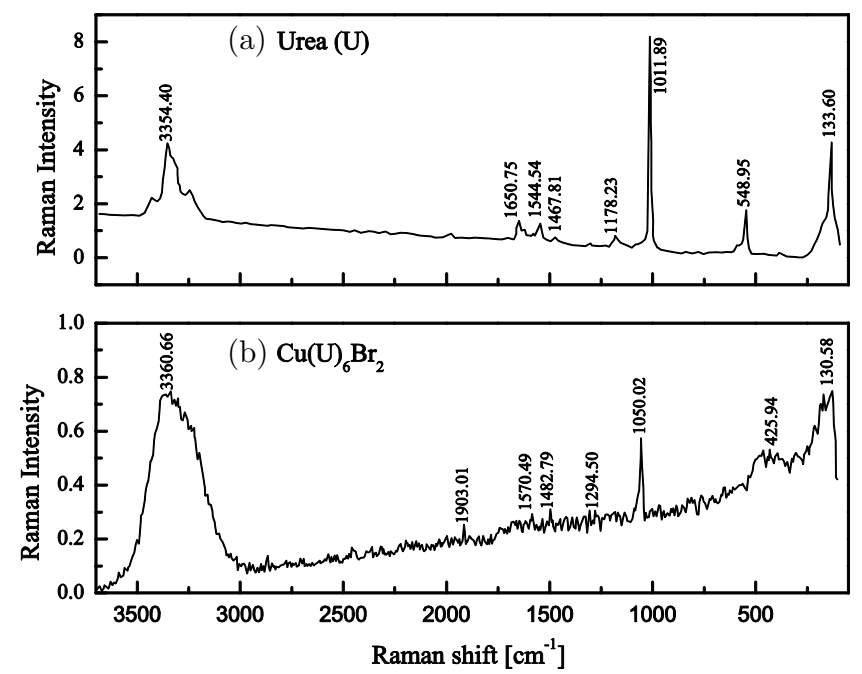

Fig. 2. Raman spectra of $U$ (a) and $\mathrm{Cu}(\mathrm{U})_{6} \mathrm{Br}_{2}$ (b). 
urea spectrum is assigned to the motion consisting of $\mathrm{C}=\mathrm{O}$ stretching and symmetric $\mathrm{C}=\mathrm{N}$ stretching which corresponds to those bands at lower wavenumbers $\left(505-520 \mathrm{~cm}^{-1}\right)$ in spectra of complexes. Such behavior originates from the weakness of double bond character between carbon and oxygen atoms, i.e., $\mathrm{C}=\mathrm{O}$. The strong band appeared at $1012 \mathrm{~cm}^{-1}$ in urea which shifts to $1050 \mathrm{~cm}^{-1}$ in all complexes which is assigned to $\mathrm{C}=\mathrm{O}$ stretching vibration.

\subsection{Dielectric study}

In order to understand the electrical behavior of urea samples, the frequency dependence of AC electrical conductivity $\left(\sigma_{\mathrm{ac}}\right)$, permittivity $\left(\varepsilon^{\prime}\right)$ and dielectric loss $\left(\varepsilon^{\prime \prime}\right)$ are firstly checked at room temperature, as shown in Figs. 3 and 4. As a general description, some changes can be noticed in the spectral features between urea and urea complexes. Figure 3(a) shows a conductivity decrease with decreasing frequency and reaches values around $10^{-11} \mathrm{~S} / \mathrm{cm}$, reflecting insulation properties. For being urea samples good insulators, the undesirable electrode polarization ${ }^{33}$ which usually affects the dielectric properties at low frequencies, is neglected. As frequency increases, the conductivity shows an increase due to the long range movements of free charge carriers. The free charge carriers we considered here are represented by the electron delocalization along urea molecule as illustrated in Scheme 1. The conductivity of urea samples shows similar behavior and identical values at frequencies lower than $3 \times 10^{3} \mathrm{~Hz}$ then becomes different at higher frequencies. The conductivity of $\mathrm{Ni}(\mathrm{U})_{6} \mathrm{Br}_{2}$ shows different spectral features

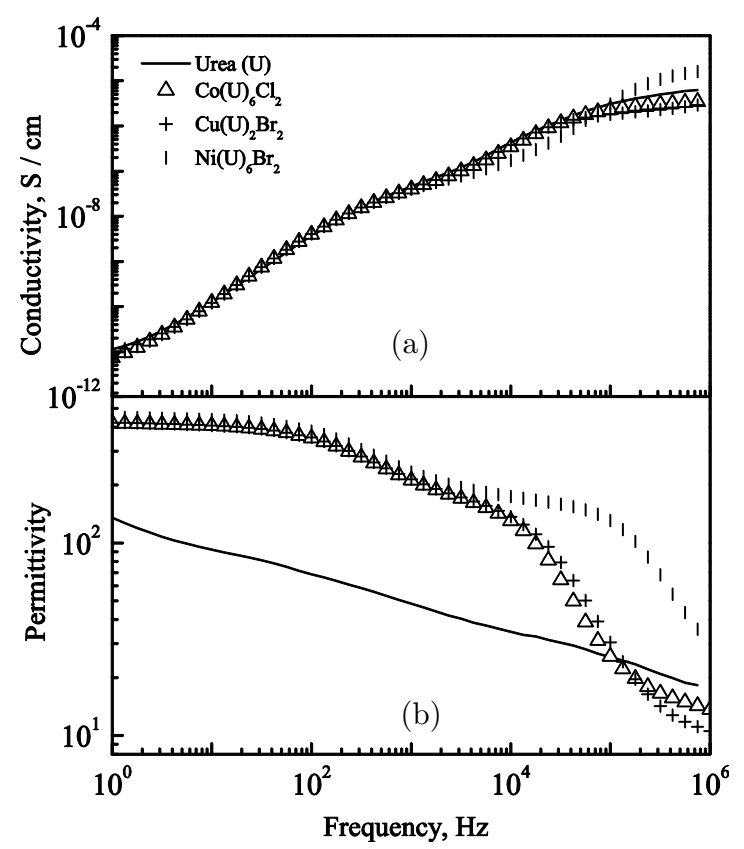

Fig. 3. The frequency dependence of conductivity $\left(\sigma_{\mathrm{ac}}\right)$ and permittivity $\left(\varepsilon^{\prime}\right)$ of pure urea $(\mathrm{U})$ and metal urea complexes at room temperature.
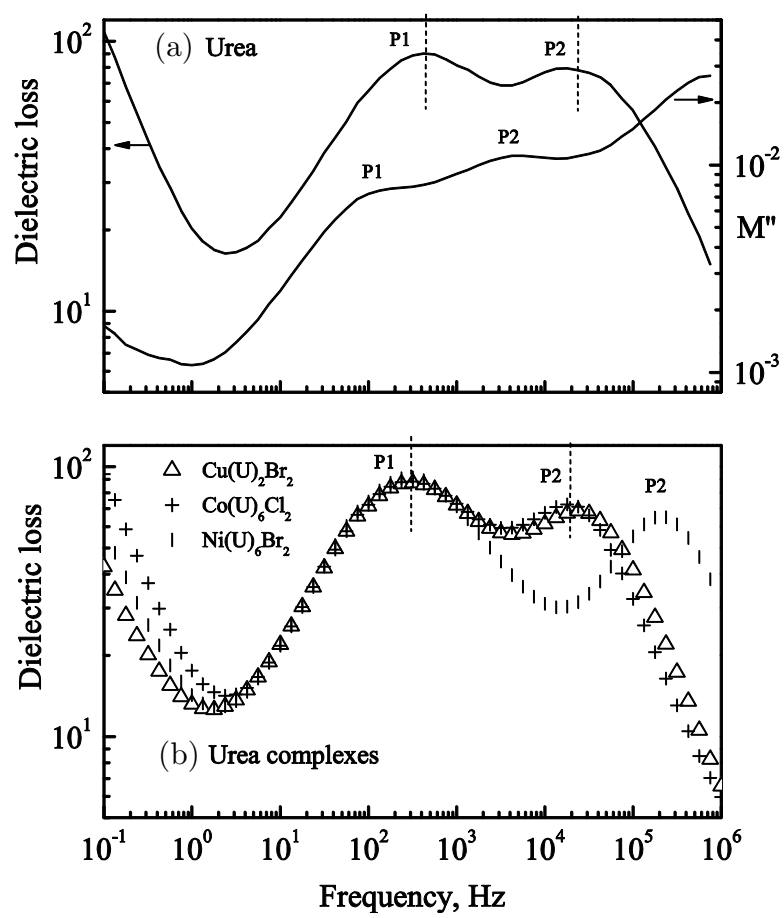

Fig. 4. The frequency dependence of dielectric loss $\left(\varepsilon^{\prime \prime}\right)$ and loss modulus $\left(M^{\prime \prime}\right)$ of pure urea $(\mathrm{U})$ shown in graph (a). The frequency dependence of $\varepsilon^{\prime \prime}$ of metal urea complexes shown in graph (b).

from those given for other samples, particularly at high frequencies.

The permittivity $\left(\varepsilon^{\prime}\right)$ signifying the material ability to store electrical charge, is also investigated (Fig. 3(b)). Generally, $\varepsilon^{\prime}$ shows high values at low frequencies then decreases as the frequency increases due to a decrease in the total polarization (TP) arising from the summation of electronic, ionic, dipolar and space charge polarization. ${ }^{34,35}$ Since at low frequencies, the time needed for dipoles or charge carriers is enough to orient themselves toward the electric field, i.e., TP increases, thus $\varepsilon^{\prime}$ increases. Conversely, with increasing frequency, the charge carriers and dipoles will not have enough time to follow the rapid changes in the applied field, i.e., TP decreases, thus $\varepsilon^{\prime}$ decreases, showing two dispersion regions. Furthermore, at frequencies lower than $8 \mathrm{~Hz}$, the permittivity of urea complexes remains almost constant whereas the dielectric loss (Fig. 4) rapidly increases with decreasing frequency. This ascribed to the charge transportation process or DC conductivity $\left(\sigma_{\mathrm{dc}}\right)$. Within this low frequency region, the free charge carriers migrate easily through the dielectric, causing DC conduction. But at higher frequencies, the charge carriers get trapped against the defect site, forming an opposite charge in its vicinity which subsequently slows down the charges motion, thus $\sigma_{\mathrm{dc}}$ decreases.

Figure 4 shows clearly two peaks at low (P1) and high frequency regions (P2), corresponding to the dispersion regions in $\varepsilon^{\prime}$ behavior reporting the Kramers-Kronig relation. ${ }^{36}$ Further, both peaks also appear in the loss 
modulus $\left(M^{\prime \prime}\right)$ - frequency representation for all samples, as shown as an example of the ligand presented in Fig. 4(a). It has been pointed out elsewhere ${ }^{37,38}$ that for a dielectric relaxation process, the relaxation peak appears in both $M^{\prime \prime}$ and $\varepsilon^{\prime \prime}$ representation. Comparisons of $M^{\prime \prime}$ and $\varepsilon^{\prime \prime}$ representations have been used to distinguish between the dielectric relaxation processes and the long-range conductivity.

In view of this, one can attribute the peaks to the real dielectric relaxation processes which are related to a part of a molecule (functional groups, etc.) or to the molecule as a whole, hence information about the dynamics molecular behavior can be obtained. Based on this, we could ascribe the low frequency relaxation peak $(\mathrm{P} 1)$ to the orientational polarization of urea molecule. However, such interpretation is questionable because no published work in the literature supports this suggestion. The peak position of $\mathrm{P} 1$ for all urea samples shows the coordination mode dependency since it is determined at constant relaxation $\left(\tau=7.6 \times 10^{-4} \mathrm{~s}\right)$ upon coordination through the same metal-oxygen bond. Besides, the peak position shift seemed to be associated to the triclinic-tetragonal phase transition. Interestingly, the dielectric measurements provide successfully a correlation between the peak position, phase and the coordination mode for all urea samples. The faster or the higher frequency relaxation peak (P2) could be related to the orientational polarization of some parts of urea molecule may be $\mathrm{NH}_{2}$ groups. However, this interpretation is also questionable. It can also be seen from Fig. 4 that the peak position of $\mathrm{P} 2$ for the ligand and $\mathrm{Co}(\mathrm{U})_{6} \mathrm{Cl}_{2}$ has constant frequency value $\left(1.8 \times 10^{4} \mathrm{~Hz}\right)$ whereas it is different for $\mathrm{Cu}(\mathrm{U})_{6} \mathrm{Br}_{2}$ and $\mathrm{Ni}(\mathrm{U})_{6} \mathrm{Br}_{2}$. In particular, $\mathrm{Ni}(\mathrm{U})_{6} \mathrm{Br}_{2}$ shows a well distinguished relaxation peak whose maximum is positioned at relatively higher frequency value than that for the other complexes. This is an indicative to a polarization increase and thus the corresponding relaxation process (P2) becomes much faster upon coordination with $\mathrm{Ni}^{2+}$ ions. This seemed to be in agreement with the changes occurring in the unit cell volume (Table 1) which shows the highest values $\left(1252.2 \AA^{3}\right)$ for $\mathrm{Ni}(\mathrm{U})_{6} \mathrm{Br}_{2}$. Since, as the volume of unit cell increases to such a particular value, the mobility of $\mathrm{NH}_{2}$ group increases, i.e., its polarization increases. Furthermore, the observed difference in P2 intensity may be associated to the difference in particle sizes of $\mathrm{Co}^{2+}, \mathrm{Cu}^{2+}$ and $\mathrm{Ni}^{2}$ ions. The peak broadness leads to the nonideal relaxation behavior predicted by Debye model. ${ }^{39}$ Therefore, in order to determine the relaxation parameters describing each relaxation peak, the complex permittivity spectrum, $\varepsilon *(\omega)=\varepsilon^{\prime \prime}(\omega)-i \varepsilon^{\prime \prime}(\omega)$ is fitted using the general semi-empirical model of two - term Havriliak-Negami ${ }^{40}$ given as:

$$
\varepsilon^{*}(\omega)=\varepsilon_{\infty}+\sum_{i=1}^{2}\left\lfloor\frac{\Delta \varepsilon_{i}}{\left(1+\left(i \omega \tau_{i}\right)^{\alpha i}\right)^{\beta i}}\right\rfloor,
$$

where $0<\alpha \leq 1$ and $0<\gamma \leq$ are the shape parameters describing the broadening of symmetrical and asymmetrical peak; $i$ indicates the number of possible relaxation processes; $\Delta \varepsilon=\varepsilon_{s}-\varepsilon_{\infty}$ is the dielectric relaxation strength which reflects the polarity of the constituents, $\varepsilon_{s}$ is the static permittivity, $\varepsilon_{\infty}$ is the permittivity at infinite frequency; $\tau(=$ $1 / 2 \pi f)$ is the relaxation time which is the time needed for the dipoles to relax to their equilibrium positions upon removal of the electric filed. As a representative example, Fig. 5 shows fitting dielectric loss spectra of the ligand (U) and $\mathrm{Ni}(\mathrm{U})_{6} \mathrm{Br}_{2}$. The obtained relaxation parameter values are listed in Table 3. It is clear that both urea samples have different fitting parameters values. For instance, the lower frequency relaxation peak $(\mathrm{P} 1)$ of $\mathrm{Ni}(\mathrm{U})_{6} \mathrm{Br}_{2}$ shows the longer relaxation time $\left(\tau=7.6 \times 10^{-4} \mathrm{~s}\right)$ as compared to that of the ligand $\left(\tau=5.7 \times 10^{-4} \mathrm{~s}\right)$. Similar behavior was found for the remaining complexes. This is in fact attributed to the differences in the sample conductivities since the metal complexes become less conductive than the ligand due to the decrease in the number of loan pair of electrons on oxygen atom upon coordination through $\mathrm{M}-\mathrm{O}$ bond. The higher frequency

Table 3. Fitting parameters values of urea $(\mathrm{U})$ and $\mathrm{Ni}(\mathrm{U})_{6} \mathrm{Br}_{2}$.

\begin{tabular}{lccccc}
\hline & \multicolumn{3}{c}{$\mathrm{U}$} & & \multicolumn{2}{c}{$\mathrm{Ni}(\mathrm{U})_{6} \mathrm{Br}_{2}$} \\
\cline { 2 - 3 } \cline { 5 - 6 } Fitting parameters & $\mathrm{HN} 1$ & $\mathrm{HN} 2$ & & $\mathrm{HN} 1$ & $\mathrm{HN} 2$ \\
\hline$\Delta \varepsilon_{i}^{\prime \prime}$ & 261 & 201 & & 299 & 140 \\
$\tau_{M}(\mathrm{~s})$ & $5.7 \times 10^{-4}$ & $6.4 \times 10^{-6}$ & $7.6 \times 10^{-4}$ & $7.5 \times 10^{-7}$ \\
$\alpha_{i}$ & 0.24 & 0.21 & & 0.26 & 0.08 \\
$\beta_{i}$ & 0.87 & 0.9 & & 0.79 & 0.95 \\
\hline
\end{tabular}

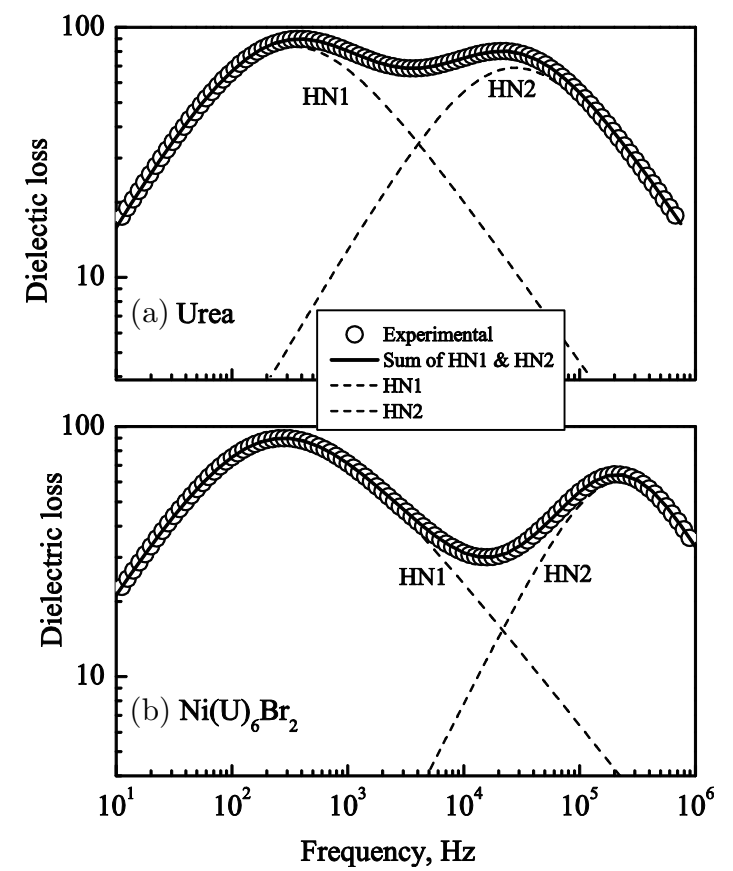

Fig. 5. Fitting of the dielectric loss spectra $\left(\varepsilon^{\prime \prime}\right)$ for $U$ (a) and $\mathrm{Ni}(\mathrm{U})_{6} \mathrm{Br}_{2}$ (b) by using two-term Havriliak-Negami $(\mathrm{HN})$ function. 


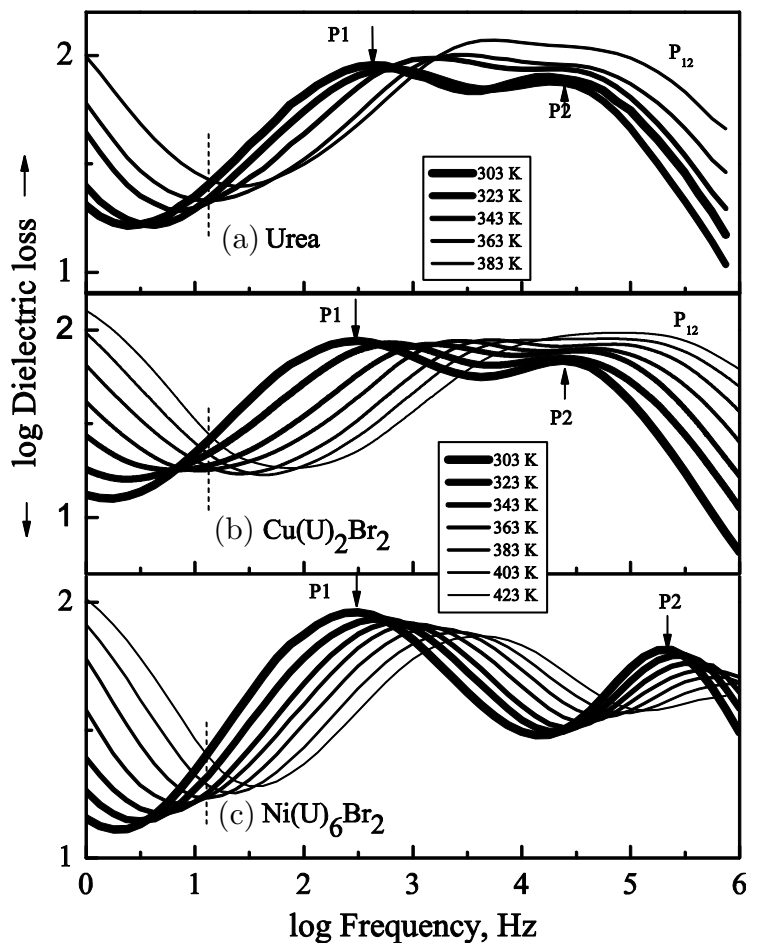

Fig. 6. The frequency and temperature dependence of dielectric loss $\left(\varepsilon^{\prime \prime}\right)$ of Urea (a), $\mathrm{Cu}(\mathrm{U})_{2} \mathrm{Br}_{2}(\mathrm{~b})$ and $\mathrm{Ni}(\mathrm{U})_{6} \mathrm{Br}_{2}(\mathrm{c})$.

relaxation peak (HN2) showed different relaxation parameters depending on the nature of each complex.

In order to investigate the influence of temperature on the observed relaxation peaks, the dielectric loss of the ligand (U), $\mathrm{Cu}(\mathrm{U})_{2} \mathrm{Br}_{2}$ and $\mathrm{Ni}(\mathrm{U})_{6} \mathrm{Br}_{2}$ is plotted versus frequency at different temperatures between 303 and $423 \mathrm{~K}$ as shown in Fig. 6. As a general description, the peak position of $\mathrm{P} 1$ is determined at the same relaxation time, i.e., $7.6 \times 10^{-4} \mathrm{~s}$ for all urea complexes whereas it shifts to lower relaxation time $\left(5.7 \times 10^{-4} \mathrm{~s}\right)$ for the ligand. Further, the peak position of $\mathrm{P} 2$ of $\mathrm{U}, \mathrm{Co}(\mathrm{U})_{6} \mathrm{Cl}_{2}$ and $\mathrm{Cu}(\mathrm{U})_{2} \mathrm{Br}_{2}$ is determined at constant relaxation time $\left(\sim 8.84 \times 10^{6} \mathrm{~s}\right)$ below $383 \mathrm{~K}$ then shifts to higher frequencies with increasing temperature. At $383 \mathrm{~K}$ or above, $\mathrm{P} 2$ merges with $\mathrm{P} 1$, displaying a broad peak $\left(\mathrm{P}_{12}\right)$ which also shifts to higher frequencies with increasing temperature. Furthermore, the spectral features of $\mathrm{Co}(\mathrm{U})_{6} \mathrm{Cl}_{2}$ and $\mathrm{Cu}(\mathrm{U})_{2} \mathrm{Br}_{2}$ seemed to be very similar, leading to that $\mathrm{Co}^{2+}$ and $\mathrm{Cu}^{2+}$ ions have similar effect on the urea dielectric properties. In contrast, for $\mathrm{Ni}(\mathrm{U})_{6} \mathrm{Br}_{2}$ (Fig. 4(c)), the spectral features are different; $\mathrm{P} 1$ and $\mathrm{P} 2$ are well distinguished by the naked eye and both shifted to higher frequencies with increasing temperature and therefore $\mathrm{P}_{12}$ disappears. As a general description, both peaks of all samples are thermally activated because they shift to higher frequency with increasing temperature.

Further inspection on Fig. 6 shows that $\varepsilon^{\prime \prime}$ rapidly increases with decreasing frequency and increasing temperature in the low frequency region indicated by the vertical dashed line, confirming once more the contribution of dc-like imperfect charge transport $\left(\sigma_{\mathrm{dc}}\right){ }^{41}$

\section{Conclusion}

$\mathrm{AC}$ measurements were carried out on the solid urea (ligand) and its complexes by means of dielectric spectroscopy over a wide frequency range $\left(0.1-10^{6} \mathrm{~Hz}\right)$ at different temperatures. The molecular structure of these samples was studied using XRD, FTIR and FT-Raman. Urea coordinates with $\mathrm{Co}^{2+}$, $\mathrm{Cu}^{2+}$ or $\mathrm{Ni}^{2+}$ ions through the same oxygen-metal bond $(\mathrm{O}-\mathrm{M})$. Upon coordination, the ligand structure transformed from polycrystalline single tetragonal phase to triclinic phase. Consequently, the permittivity of urea complexes shows much higher values as compared to those of pure urea. $\mathrm{Co}^{2+}$ and $\mathrm{Cu}^{2+}$ ions found to have similar effect on the urea dielectric properties. In contrast, $\mathrm{Ni}^{2+}$ ions have different effect particularly in the high frequency region. Furthermore, two relaxation peaks were observed in the dielectric loss spectra which can be related to a part of a molecule $\left(\mathrm{NH}_{2}\right.$ - groups) or to the urea molecule as a whole. Both peaks shift to higher frequency with increasing temperature corresponding to thermally activated. Position of the low frequency relaxation peak seemed to be correlated with the coordination mode. The prepared urea complexes may be useful in agriculture, medicine and healthy sciences.

\section{Acknowledgments}

This work was supported by National Research Centre (NRC), Cairo, Egypt. I am thankful to Prof. Dr. Ahmed Ghoneim; Professor of Dielectrics who shared his knowledge and expertize that greatly assisted in this work.

\section{References}

${ }^{1}$ J. Walker and J. K. Wood, LIV- Hydrolysis of urea hydrochloride, J. Chem. Sot. 83, 484 (1903).

${ }^{2}$ G. C. Catella, J. H. Bohn and J. R. Luken, Tunable high power urea optical parametric oscillator, IEEE J. Quantum Electron 24, 1201 (1988).

${ }^{3}$ L. Zeng, M. Zha, M. Aridoino, P. Franzosi, L. Zanotti, G. Zuccalli and C. Paorici, Solution crystal growth of urea for nonlinear optical applications, J. Cryst. Growth 166, 528 (1996).

${ }^{4}$ V. G. Dmitriev, G. G. Gurzadyan and D. N. Nikogosyam, Handbook of Nonlinear Optical Crystals, 2nd edn. (Springer Verlag, Berlin Heidelberg, New York, 1997).

${ }^{5}$ W. F. Boron and E. L. Boulpaep, Medical Physiology, updated edn. (Saunders, Philadelphia, USA, 2004).

${ }^{6}$ J. H. Meessen and H. Petersen, Urea in Ullmann's Encyclopedia of Industrial Chemistry, Electronic Release, 6th edn. (Wiley-VCH, Weinheim, Germany, 2002).

${ }^{7}$ M. C. Schroeder, J. M. Hamby, C. J. C. Connolly, P. J. Grohar, R. T. Winters, M. R. Barvian, C. W. Moore, S. L. Boushelle, S. M. Crean, A. J. Kraker, D. L. Driscoll, P. W. Vincent, W. L. Elliott, 
G. H. Lu, B. L. Batley, T. K. Dahring, T. C. Major, R. L. Panek, A. M. Doherty and H. D. Hollis Showalter, Soluble 2-substituted aminopyrido [2,3-d] pyrimidin-7-yl ureas. Structure-activity relationships against selected tyrosine kinases and exploration of in vitro and in vivo anticancer activity, J. Med. Chem. 44(12), 1915 (2001).

${ }^{8}$ B. K. Kaymakcioglu, S. Rollas, E. Körcegez and F. Ari cioglu, Synthesis and biological evaluation of new N-substituted-N'-(3,5di/1,3,5-trimethylpyrazole-4-yl)thiourea/urea derivatives, Eur. J. Pharm. Sci. 26, 97 (2005).

${ }^{9}$ J. H. Meessen and H. Petersen, Urea, Ullmann's Encyclopedia of Industrial Chemistry, 5th edn. (John Wiley \& Sons, Weinheim, 2005).

${ }^{10}$ Y. K. Kim, J. W. Williard and A. W. Frazier, Solubility relationship in the system sodium nitrate-ammonium nitrate-urea-water at 0.degree.C, J. Chem. Eng. Data 33, 306 (1988).

${ }^{11}$ D. Guy, A. Caroline, K. F. Gankam and S. Alain, Treatment of euvolemic hyponatremia in the intensive care unit by urea, Critical Care 14, 1 (2014).

${ }^{12}$ J. O. Greenhalf and P. L. C. Diggory, Induction of therapeutic abortion by intra-amniotic injection of urea, British Medical Journal 1 (5739), 28 (1971).

${ }^{13}$ A. R. Yamaguchi, B. Penland, S. Mizushima, T. J. Lane, C. Curran and J. V. Quagliano, Infrared absorption spectra of inorganic coördination complexes. XIV. infrared studies of some metal thiourea complexes, J. Amer. Chem. Soc 80, 527 (1958).

${ }^{14}$ G. B. Aitken, J. L. Duncan and G. P. Mc Quillan, Normal coordinates for the planar vibrations of thiourea, and frequency assignment for selenourea, J. Chem. Soc. A 2695 (1971).

${ }^{15}$ D. Hadzi, J. Kidric, Z. V. Knezevic and B. Barlic, The normal coordinate analysis of urea, thiourea, and thier isotopic analogues in the solid phase and in solution, Spectrochim. Acta, Part A 32, 693 (1976).

${ }^{16} \mathrm{P}$. S. Gentile, J. White and S. Haddad, The crystal structure of tetrakis(urea) cobalt(II) nitrate, Inorg. Chim Acta 8, 97 (1974).

${ }^{17}$ D. S. Sagatys, R. C. Bott, G. Smith, K. A. Byriel and C. H. L. Kennard, The preparation and crystal structure of a polymeric (1:1) Silver nitrate urea complex $\left[\left(\mathrm{AgNO}_{3}\right)_{2}\left(\mathrm{CH}_{4} \mathrm{~N}_{2} \mathrm{O}\right)_{2}\right]_{n}$, Polyhedron 11, 49 (1992).

${ }^{18}$ B. A. EL-Sayed, A. A. A. Emara, F. S. M. Abd Elhameed and S. M. Shaaban, Temperature dependence of the electrical conductivity of selenous acid and its transition metal selenites, Mater. Lett 27, 247 (1996).

${ }^{19}$ M. Abd EL-Mottaleb, H. A. Hammad, S. M. Shaaban and M. M. EL-Desoky, Electrical conductivity and phase transition studies of some selected Congo red-metal complexes, J. Therm. Anal 46, 1459 (1996)

${ }^{20}$ B. A. EL-Sayed, M. M. EL-Desoky, S. M. Shaaban and M. B. Sayed, Electrical and spectral studies of solid organic semiconductors - I. Structural interpretation of promoted conductivity of salicylaldazine, Electrochim. Acta 35, 1987 (1990).

${ }^{21}$ M. M. Sallam, B. A. EL-Sayed and S. M. Shaaban, Electrical transport as a function of temperature in urea and cobalt (III)-urea complex, J. Mater. Sci.- Mater. Electron 10, 479 (1999).

${ }^{22}$ E. H. Grant, S. E. Keefe and R. Shack, Advances in Molecular Relaxation Processes (Elsevier Publishing Company, Amsterdam, Netherlands, 1972), pp. 217-228.
${ }^{23}$ D. B. W. Yawney and R. J. Doedens, Crystal and molecular structure of copper (II) formate monourea, Inorg. Chem. 9, 1626 (1970).

${ }^{24}$ V. Yadav, A. Kumar, S. Sharan and A. K. Sinha, Analyses of dielectric properties of fertilizers (urea and diammonium phosphate) in aqueous solution at different temperatures in microwave frequency, Int. J. Phys. Sci. 5, 2466 (2010).

${ }^{25}$ J. B. Bateman, C. Gabriel, F. G. Evans and E. H. Grant, Dielectric properties of urea and acetamide in aqueous solution, J. Chem. Soc. Faraday Trans. 86, 321 (1990).

${ }^{26}$ J. Jadzyn, L. Bouteiller, J.-L. Dejardin and G. Czechowski, Dielectric relaxation in hydrogen bonded urea-based supramolecular polymer N, N'-di (2,2-dipentylheptyl) urea, Acta Phys. Pol. A 110, 495 (2006).

${ }^{27}$ O. B. Ibrahim, Complexes of urea with $\mathrm{Mn}(\mathrm{II}), \mathrm{Fe}(\mathrm{III}), \mathrm{Co}(\mathrm{II})$, and $\mathrm{Cu}(\mathrm{II})$ metal ions, Adv. Appl. Sci. Res. 3, 3522 (2012).

${ }^{28}$ E. V. Savinkinaa, D. V. Golubev, M. S. Grigoriev and D. V. Albov, Iodine networks in polyiodides of M(III) urea complexes: Crystal structures of $\left[\mathrm{V}(\mathrm{Ur})_{6}\right][\mathrm{I} 3]_{3}$ and $\left[\mathrm{Dy}(\mathrm{Ur})_{8}\right]\left[\mathrm{I}_{5}\right]\left[\mathrm{I}_{3}\right]_{2}\left[\mathrm{I}_{2}\right]$, Polyhedron 54, 140 (2013).

${ }^{29}$ R. B. Penland, S. Mizushima, C. J. Curran and V. Quagliano, Infrared absorption spectra of inorganic coördination complexes. $\mathrm{X}$. studies of some metal-urea complexes, J. Am. Chem. Soc. 79, 1575 (1957).

${ }^{30}$ T. Theophanides and P. D. Harvey, Structural and spectroscopic properties of metal-urea complexes, Coord. Chem. Rev. 76, 237 (1987).

${ }^{31}$ N. Mario, C. Leandro and A. Giampaolo, Structure of cadmium chloride-monomethylurea, Gazz. Chim. Ital. 88, 235 (1958).

${ }^{32}$ R. M. Fuoss and J. G. Kirkwood, Electrical properties of solids. VIII. dipole moments in polyvinyl chloride-diphenyl systems, J. Am Chem. Soc. 63, 385 (1941).

${ }^{33}$ S. M. Shaaban, B. A. El-Sayed, A. A. Shaban and A. M. Hassan, Temperature dependence of the electrical conductivity of urea and thiourea, Mater. Lett. 21, 255 (1994).

${ }^{34}$ R. W. Wagner, Erklarung der dilectricshen-narchwirkugen auf grund maxwellscher vorstellungen, Arch Electrotech 2, 371 (1914).

${ }^{35}$ R. W. Sillars, The properties of dielectrics containing semiconducting particles various shapes, Inst. Elect. Eng. 80, 378 (1937).

${ }^{36}$ C. Elissalde and J. Ravez, Ferroelectric ceramics: Defects and dielectric relaxation, J. Mater. Chem. 11, 1957 (2001).

${ }^{37}$ I. M. Hodge, M. D. Ingram and A. R. West, Impedance and modulus spectroscopy of polycrystalline solid electrolytes, J. Electroanal. Chem. 74, 125 (1976).

${ }^{38} \mathrm{R}$. Gerhardt, Impedance and dielectric spectroscopy revisited: Distinguishing localized relaxation from long-range conductivity, J. Phys. Chem. Solids 55, 1491 (1994).

${ }^{39}$ P. Debye, Polar Molecules, Chemical Catalog (Dover Publications, New York, USA, 1929).

${ }^{40} \mathrm{~S}$. Havriliak and S. Negami, A complex plane representation of dielectric and mechanical relaxation processes in some polymers, Polymers 8, 161 (1967).

${ }^{41}$ A. K. Jonscher, Dielectric Relaxation in Solids, 1st edn. (Chelsea Dielectric Press, London, 1983). 